\title{
EDUCAÇÃO DO CORPO NO ENSINO FUNDAMENTAL: REFLEX ÕES A PARTIR DO COTIDIANO DE UMA ESCOLA PÚBLICA
}

\author{
Danielle Angelo Bargas ${ }^{\mathrm{i}}$ \\ Eliana Ayoub ${ }^{\text {ii }}$ \\ Dolores Setuval Assaritti ${ }^{\mathrm{iii}}$ \\ Juliana Scarazzatto ${ }^{\text {iv }}$ \\ Marília Del Ponte de Assis ${ }^{\mathrm{v}}$
}

\begin{abstract}
Resumo: Este artigo resulta de uma pesquisa qualitativa com objetivo de refletir sobre a educação do corpo nos espaços-tempos do cotidiano escolar. Por meio de uma pesquisa de campo em uma escola estadual da cidade de Campinas/SP, buscamos compreender como as crianças experimentam um minucioso processo de educação, que se faz também e fundamentalmente, no corpo e pelo corpo. Observarmos que a educação do corpo faz parte de um processo que sempre esteve presente na escola, com práticas que ensinam, sobretudo, a controlar as manifestações corporais e a gestualidade das crianças. Entretanto, trata-se de um processo amplo, no qual também identificamos que nas brechas do cotidiano há espaços em que o controle escapa e tanto professores como crianças vivem outras relações no contexto escolar.
\end{abstract}

Palavras-chave: Educação do corpo; Gestualidade; Ensino Fundamental.

\begin{abstract}
This article results from qualitative research with the objective of reflecting about body education in the spaces-times of the school routine. Through field research in a public school in the city of Campinas/SP, we sought to understand how children experience a meticulous education process that is made, also and fundamentally, in the body and through the body. We observed that the body education is part of a process that has always been present in the school, with teaching practices that teach, above all, to control the children's corporal manifestations and gestures. However, it is an extensive process, which we also identified that, in the daily gaps, the control escapes and both teachers and children can live other relationships in the school context.
\end{abstract}

Keywords: Body education; Gesture; Elementary school.

\section{Introdução}

A educação escolar se constitui em meio a um conjunto de condições que precisam ser constantemente discutidas e problematizadas, dentre as quais podemos destacar os currículos escolares, as políticas públicas, a falta de recursos, os baixos

2020 Bargas; Ayoub; Assaritti, Scarazzatto, Assis. Este é um artigo de acesso aberto distribuído sob os termos da Licença Creative Commons Atribuição Não Comercial-Compartilha Igual (CC BY-NC-4.0), que permite uso, distribuição e reprodução para fins não comerciais, com a citação dos autores e da fonte original e sob a mesma licença. 


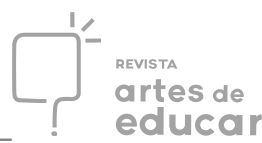

salários, os conflitos sociais etc. Todos esses aspectos merecem reconhecimento e estudo aprofundado, porém certas questões são privilegiadas enquanto outras são recorrentemente negligenciadas numa hierarquia de importância decorrente de fatores históricos e culturais inerentes à instituição escolar.

A educação do corpo é um exemplo da negligência a certos aspectos, pois apesar de intrínseca ao cotidiano escolar, não é comumente debatida na escola.

A despeito dessa constatação, podemos seguir seus traços, vestígios e contornos, e encontrar a educação do corpo presente em muitos momentos do cotidiano escolar. Apoiando-nos em Soares (2014), entendemos que

A educação em geral e a educação do corpo, de modo bem específico e especializado, incidem diretamente sobre os corpos, transmitindo valores e normas, difundindo significados e sentidos que implicam a elaboração de comportamentos e atitudes aceitos socialmente. (SOARES, 2014, p. 220)

Trata-se de um processo complexo, que modula as relações sociais. Ainda de acordo com a autora,

a noção de educação do corpo caracteriza-se pela progressiva repressão das manifestações corporais naquilo que parece ser incontrolável. Educar o corpo vem sendo, desse modo, torná-lo adequado ao convívio social e inseri-lo em processos de aprendizagens que buscam encobrir e apagar uma natureza rebelde, trazendo à luz uma natureza pacificada. (SOARES, 2014, p. 221)

Portanto, a educação que se dá pelo/no corpo tem operado como repressão das manifestações corporais, coibição dos gestos e da expressão corporal, e imposto padrões de comportamento socialmente aceitos. As diversas sociedades definem esses padrões e somos convidados/as (ou obrigados/as) a frequentar instituições que têm entre seus objetivos instaurar uma disciplina dos corpos, de forma a torná-los obedientes, ajustados de acordo com a lógica própria de cada instituição. Dentre elas está a escola, "uma instituição disciplinar por excelência".

$\mathrm{Na}$ discussão sobre os mecanismos disciplinares encontrados nas sociedades modernas, Foucault (1987) se torna referência ao trazer a instigante correlação entre o poder e a disciplina sobre os corpos. Para Foucault (1987; 2012), o exercício do poder 


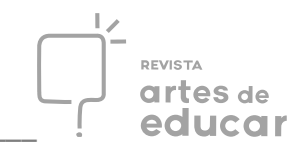

incide nos corpos, estando presente em todas as relações sociais em sua materialidade. Com isso, não há uma única via de manifestação do poder, mas sim, práticas cotidianas que se apresentam em todos os lugares, principalmente em instituições disciplinares como os presídios, os hospitais, as escolas, as fábricas, os quartéis.

A disciplina incide diretamente sobre o corpo - objeto e alvo de poder - o qual se manipula, se modela, se treina,[corpo] que obedece, responde, se torna hábil ou cujas forças se multiplicam (FOUCAULT, 1987, p. 125). E quando o corpo é submetido, utilizado, transformado e, principalmente, disciplinado, ele se torna dócil e eficiente diante das exigências dos diferentes sistemas disciplinares. No caso específico da instituição escolar, Foucault (1987) nos permite identificar os mecanismos disciplinares que estão arraigados no cotidiano da escola. Tais mecanismos se apresentam sob diversas formas: na arquitetura, no controle do tempo, nas relações hierárquicas, na vigilância, na lógica avaliativa e nas punições.

A imposição da disciplina escolar necessita de um aparato adequado para funcionar, e a estrutura arquitetônica, na qual os sujeitos são facilmente vistos, vigiados e controlados, é um importante aspecto. Soares e Zarankin (2004) repercutem essa ideia:

As formas atuais das escolas, as prisões, os hospitais, as moradias familiares, as cidades em seu conjunto representam um modelo de sociedade, um modelo de indivíduo adequado e útil ao sistema predominante. Desigualdade, individualismo, vigilância, controle, flexibilidade, complexidade, hierarquia, são componentes frequentes de qualquer prédio moderno (SOARES; ZARANKIN, 2004, p. 28).

Os detalhes da estrutura física das escolas são cuidadosamente planejados e construídos. Sua própria organização em séries, classes, fileiras, colabora para o controle das atividades e ações dos sujeitos. Rotinas que, ao se repetirem, constroem modelos de indivíduos. A arquitetura não pode ser pensada como uma prática humana neutra, pois sua mensagem marca, para sempre, os nossos corpos (SOARES; ZARANKIN, 2004, p. 28).

De maneira geral, as salas de aula que compõem a rede pública e privada de ensino são quadriláteras, com paredes extensas, que não permitem comunicação com outros espaços. As janelas são altas e com grades, o pátio com muros, portões que Revista Interinstitucional Artes de Educar. Rio de Janeiro, V. 6, N.1- pág. 13-36 janeiro-abril de 


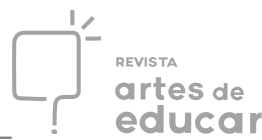

impedem a visão para a área externa, ou seja, tudo é pensado para permitir vigiar as atividades dos/as alunos/as, professores/as, funcionários/as, enfim, daqueles/as que circulam no espaço escolar.

No que se refere ao controle do tempo, ele está diretamente ligado à busca de eficiência, à produção e às múltiplas formas de avaliação. Deve-se aproveitar ao máximo todos os minutos para produzir e gerar números que servirão de parâmetro para os indicadores das avaliações internas e externas. Assim, o desafio posto à escola não é simplesmente cumprir horários, mas garantir a produtividade no tempo disponível, retirando do cenário tudo que possa perturbar ou distrair.

Todo esse sistema de vigilância se desenrola de maneira rigidamente hierarquizada: a secretaria de ensino público controla a gestão da escola, que controla a produção do/a professor/a que, por sua vez, controla todas as atividades do/a estudante, numa busca constante pela eficiência no uso do tempo.

Outro mecanismo disciplinador presente no contexto escolar é o exame. As avaliações a que os/as alunos/as estão expostos constantemente objetivam atribuir notas (na maioria das vezes não descritivas, mas sim numéricas) para classificá-los/as e compará-los/as. Além disso, as avaliações costumam ser padronizadas e aplicadas de forma sistemática e objetiva, em horários predefinidos, e com proibição de comunicação e de movimento, claro exemplo de como o corpo é constrangido a se adequar às imposições das instâncias de controle.

Esse amplo contexto de controle disciplinar configura também, um sistema punitivo capaz de acionar "micropenalidades" toda vez que detecta a desobediência às normas. O manejo de tais penalidades se dá proporcionalmente à percepção da possibilidade de perda do controle. Citamos Foucault (1987):

$\mathrm{Na}$ oficina, na escola, no exército funciona como repressora toda uma micropenalidade do tempo (atrasos, ausências, interrupções das tarefas), das atividades (desatenção, negligência, falta de zelo), nas maneiras de ser (grosseira, desobediência), dos discursos (tagarelice, insolência), do corpo (atitudes incorretas, gestos não conformes, sujeira), da sexualidade (imodéstia, indecência). (FOUCAULT, 1987, p. 159)

Desse modo, torna-se necessário à disciplina escolar um investimento dirigido sobre o controle do corpo. Cruz et al. (2010), em seu estudo sobre a temática 


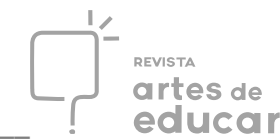

do corpo e a da infância, com base em concepções foucaultianas, esclarecem este ponto: um investimento no corpo, ensinando-lhe padrões de disciplina e de destreza, de higiene, de 'boa' postura, e mesmo de etiqueta, de retórica e de apreciação do belo (p. 60). Assim, na instituição escolar é comum encontrarmos exemplos cotidianos nessa direção:

$\mathrm{Na}$ escola é proibido falar durante a aula, tem que sentar na posição correta para não agredir a coluna, não pode levantar-se da cadeira, é preciso levantar a mão para falar, para dizer que precisa ir ao banheiro. No recreio não deve correr para não cair, é aconselhável não brincar com terra porque suja o corpo e o material escolar, não pode ir beber água o tempo todo, durante as atividades não pode olhar de lado nem conversar com o colega. (BARBOSA, 2007, p. 2)

Se nos remetemos às nossas próprias memórias do período em que fomos alunos/as na escola, facilmente nos enxergamos na situação acima descrita, sendo vigiados/as e forçados/as a nos conformar às normas. Por outro lado, tendo em vista que somos constituídos/as nas relações sociais de poder, somos também atores nessas relações e, por vezes, operamos nas frestas do sistema, exercitando possibilidades de resistência que nos auxiliam a, por vezes, escapar do controle. Basta lembrar das incessantes idas ao banheiro, das correrias no pátio e do barulho nas salas de aula, formas de resistência frente aos/às professores/as, à direção da escola e até mesmo modos de enfrentamento às paredes e cadeiras, obstáculos limitadores de nossas possibilidades de movimentação. Com isto queremos dizer que, por mais violento que seja o poder disciplinar que está presente na escola, encontram-se brechas para resistir, e devemos reconhecer que, afinal, as relações de poder na escola são atravessadas pelas resistências dos/as alunos/as.

As reflexões acima nos permitem pensar que a disciplina que incide sobre o corpo na escola constitui um cuidadoso processo de educação muitas vezes naturalizado pelos sujeitos que compõem a comunidade escolar. Questionar as muitas naturalizações, duvidar daquilo que é dado como certo e imutável é nossa função como professores/as e pesquisadores/as.

Essas inquietações nos mobilizaram a realizar uma investigação qualitativa

${ }^{6}$ sobre a educação do corpo nos espaços-tempos do cotidiano escolar, a qual envolveu uma pesquisa de campo numa escola estadual da cidade de Campinas/SP. 


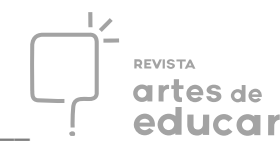

Durante a investigação, acompanhamos e registramos a rotina de duas turmas de $1^{\circ}$ ano do ensino fundamental, com a intenção de compreender como essas crianças recém-chegadas da educação infantil experimentam o minucioso processo de educação que se faz também e fundamentalmente no corpo e pelo corpo.

Com base na análise dos dados e achados da pesquisa de campo, buscamos problematizar a educação do corpo na instituição escolar (especificamente no contexto do $1^{\circ}$ ano do ensino fundamental), entendendo, conforme explicitado anteriormente, que a escola tem se configurado como um espaço da não-mobilidade, que repreende as manifestações corporais, que coíbe os gestos e a expressão corporal das crianças, e que busca a moldar uma "natureza pacificada" ou "dócil" por meio de diferentes processos de aprendizado.

\section{O cenário da pesquisa de campo}

A pesquisa de campo deste estudo ocorreu ao longo de 2014 em uma escola pública estadual da cidade de Campinas/SP, que atende crianças de seis a dez anos dos anos iniciais do ensino fundamental I ( $1^{\circ}$ ao $5^{\circ}$ ano). Foram adotados como procedimentos metodológicos a observação sistemática - com acompanhamento das atividades, registros em diário de campo e fotografias - e realização de entrevistas com as professoras.

Foram observadas duas turmas do $1^{\circ}$ ano do ensino fundamental I, compostas por cerca de 25 crianças com seis a sete anos, e suas respectivas professoras. No primeiro semestre, a investigação foi realizada com o $1^{\circ}$ ano A no período da manhã, sob responsabilidade da Prof. ${ }^{a}$ Carol; e no segundo semestre, com o $1^{\circ}$ ano B no período da tarde, com a Prof. $^{\text {a }}$ Sara. As observações semanais totalizaram aproximadamente 100 horas com cada turma, envolvendo o acompanhamento de todas as atividades tanto em sala de aula quanto em outras aulas específicas - como Educação Física e Artes - além dos momentos de recreio, entrada e de saída da escola.

Nas observações realizadas, tomamos como referência um desafio proposto por Tura (2003): 


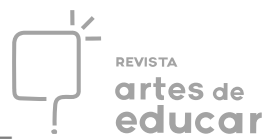

a observação pressupõe o envolvimento do pesquisador em múltiplas ações, entre elas o registrar, narrar e situar acontecimentos do cotidiano com uma intenção precípua. Envolve também a formulação de hipóteses ou questões, o planejamento, a análise, a descoberta de diferentes formas de interlocução com os sujeitos ativos da realidade investigada e, certamente, a análise do próprio modo segundo o qual o pesquisador olha seu objeto de estudo. (TURA, 2003, p.187-188)

As entrevistas foram realizadas com as duas professoras responsáveis pelas turmas (Prof. ${ }^{a}$ Carol e Prof. ${ }^{a}$ Sara), e também com a professora de Educação Física (Prof. ${ }^{a}$ Helena), a partir da seguinte pergunta geradora: Como você vê o espaço do corpo na escola?. Tínhamos a intenção que as professoras se sentissem à vontade para narrar suas ideias em torno da temática da educação do corpo na instituição escolar. Cada entrevista teve duração de 30 a 40 minutos, e as gravações foram transcritas para fins de análise e encaminhadas para as professoras, para revisão e aprovação de sua utilização. As participantes assinaram o Termo de Consentimento Livre e Esclarecido (TCLE), e atribuímos nomes fictícios para a preservação das identidades.

Entre múltiplas ações, o/a pesquisador/a continuamente reorganiza suas relações com o objeto pesquisado, levando em consideração as diversas interlocuções que se produzem com os sujeitos do contexto investigado, considerando-se em constante processo de realização. Nessa linha de reflexão, Guedes-Pinto e Fontana (2006) recomendam, sobretudo, a necessidade de abordar o cotidiano escolar não como um produto - o que é; mas como um processo em realização - o que está sendo (p. 85). Essa ideia pautou nossa pesquisa, durante a qual ficou claro o quão importante é olhar para o cotidiano escolar não como algo pronto, mas como algo vivo, em contínua transformação, como um processo dinâmico que requer um olhar atento e sensível ao ser analisado.

No que se diz respeito à análise dos dados, pautamo-nos no paradigma indiciário (GINZBURG, 1989), em busca de indícios, pistas, vestígios e sinais que nos permitissem compreender possíveis sentidos e significações em circulação na escola acerca da educação do corpo, principalmente no contexto das relações entre adultos e crianças de seis a sete anos, as quais estão experimentando um momento de transição da educação infantil para o ensino fundamental. 


\section{O cotidiano da escola e a educação do corpo}

A experiência com as duas turmas e suas professoras durante a pesquisa de campo foi necessária para vivenciarmos de perto a dinâmica do cotidiano escolar, bem como as diferentes formas com que as relações de poder se configuram dentro de uma mesma instituição.

A escola, apesar de apresentar-se como sede de intensas relações de poder, não se configura como espaço puramente de disciplinamento e silenciamento, afinal não há poder que imobilize por completo os sujeitos. O poder, para Foucault (2012), é exercido pelos sujeitos nas ações cotidianas e nas resistências diárias, devendo

ser analisado como algo que circula, ou melhor, como algo que só funciona em cadeia. Nunca está localizado aqui ou ali, nunca está nas mãos de alguns, nunca é apropriado como uma riqueza ou um bem. O poder funciona e se exerce em rede, [...] não se aplica aos indivíduos, passa por eles. (FOUCAULT, 2012, p. 183)

Foucault mostra que as relações de poder permeiam a nossa vida social, pressupondo uma constante resistência. Nesse sentido, as crianças relutam e mostramnos sua criatividade ao reagir de maneiras diversificadas ao que é imposto a elas dentro da escola, como, por exemplo, as cadeiras enfileiradas. Elas resistem em manter-se o tempo todo quietas e sentadas, e encontram pretextos para burlar o imobilismo que é muitas vezes imposto na sala de aula.

Observando o dia-a-dia da escola, constatamos que a educação do corpo estava presente nos mais diversos espaços-tempos, não somente na sala de aula, mas também no parque, na quadra, nos horários de entrada/saída, no recreio e nas aulas de Educação Física.

De segunda a sexta-feira, às $7 \mathrm{~h} 15$ da manhã ou às $13 \mathrm{~h} 15$ da tarde, crianças de seis a dez anos de idade se reuniam no pátio da escola e eram recepcionadas por um sinal sonoro, que se assemelhava a um alerta dizendo que chegou a hora de começar a disciplina. A inspetora estava a postos para garantir a ordem e repreendia com naturalidade a expressão corporal dos alunos: "chega de correr!"; "vocês nem 


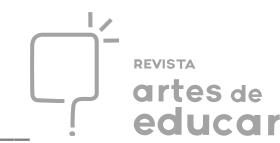

chegaram direito e já estão a todo vapor"; "fiquem mais quietos e se comportem". Enfileiradas, como de costume, por ordem de tamanho, separadas por gênero, as crianças eram orientadas, cerceadas, proibidas de ir e vir pelo pátio. Meninas e meninos separados aguardavam ansiosos e inquietos a professora da turma chegar para seguirem enfileirados até as salas de aula.

Diante de tantas normas, refletimos sobre a necessidade de um alerta, de uma fila (ainda mais apartando meninos e meninas) ou de uma bronca. E se as crianças ouvissem música, cantassem ou fossem se organizando de outras formas para irem sozinhas até as salas de aula? Impossível? Talvez não.

Logo nos primeiros dias de observação da turma do $1^{\circ}$ ano $\mathrm{A}$, constatamos o incômodo em relação às manifestações corporais das crianças. Percebemos que os gestos mais simples como levantar da cadeira, andar pela sala, jogar os papéis no lixo, até o famoso "ir ao banheiro", atraíam atitudes repreensivas da professora, que repetia quase como um refrão: "não pode ficar levantando"; "não pode ir ao banheiro"; "não pode ficar andando pela sala". Chamou-nos atenção aquela forma de controle incidindo diretamente sobre os gestos dos/as alunos/as, sobre seus corpos, suas ações, sua expressão corporal: estávamos testemunhando o exercício dos micropoderes de que já falamos.

Dentro da sala de aula desse $1^{\circ}$ ano, as crianças possuíam lugares predeterminados em fileiras, uma atrás da outra, os olhos direcionados para a frente, para a lousa, para a professora. Reafirmando a perspectiva de Cruz et al (2010):

A escola, em sua organização espacial, com uma carteira atrás da outra, se aproxima da arquitetura de uma missa permanente, na qual cada um se localiza atrás do outro, à espera daquele que tem o poder e o direito da fala: o pastor, o professor. Isto porque o modelo de bom comportamento e de seriedade ainda se define, em grande medida, pela ausência de movimento nas crianças. (CRUZ et al., 2010, p. 61)

A professora dessa turma baseava-se claramente nesse "modelo de bom comportamento e de seriedade", com regras e disciplina corporal. Na entrevista que realizamos com ela, a Prof. ${ }^{a}$ Carol trouxe algumas informações sobre sua história escolar: 


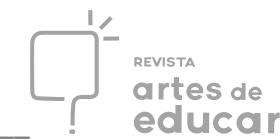

Estudei em uma escola particular, onde fiquei até o final do ginásio. Era uma escola católica de freiras, tradicional, rigorosa, a alfabetização era com a cartilha "Caminho Suave" e até postura para leitura, o professor de português cobrava. Eu tinha que ficar de pé para fazer a leitura quando ele pedia, segurava o livro na posição certa, com uma postura da coluna, postura de leitor mesmo. Ele dava poesia para a gente decorar... (Prof. ${ }^{a}$ Carol)

Com formação no Magistério e em Pedagogia, a Prof. ${ }^{a}$ Carol trabalhava a partir de um planejamento semanal, composto por conteúdos de livros e apostilas, por sua vez estipulados pela secretaria de educação do Estado, que estabelecia metas a serem alcançadas e objetivos a serem atingidos. Para cumprir tal programa, a Prof. ${ }^{a}$ Carol acreditava necessário "enquadrar" a postura dos/as alunos/as.

Eu coloquei em grupos de quatro alunos, mas eles têm que estar arrumadinhos. Às vezes eu olho aquilo... é instinto mesmo, não é coisa que eu penso antes, eu tenho que ir lá e arrumar a carteira no lugar e a postura deles, isso eu cobro também". (Prof. ${ }^{a}$ Carol)

Ela tinha clareza de que estava reproduzindo as mesmas práticas que lhe foram apresentadas durante o Magistério:

No Magistério, a gente aprende isso também. Até como apagar a lousa. A professora de prática exigia. Quando íamos fazer estágio e apresentar algo para ela, ela observava nossa postura para apagar lousa, para não gerar muito pó. O que eu aprendi no Magistério sobre corpo era postura [...] e eu cobro isso dos meus alunos. (Prof. ${ }^{a}$ Carol)

O depoimento da Prof. ${ }^{a}$ Carol remete-nos aos manuais de civilidade difundidos a partir do século XVI, os quais, segundo Fontana (2011, p. 13), prescreviam regras de uso do corpo e normas de como se apresentar em diferentes âmbitos das relações sociais. Gradativamente, consolidou-se uma forma de contenção e de autocontrole do corpo, que alcançou os corpos dos professores e as exigências que lhes passaram a ser feitas no exercício do magistério (FONTANA, 2011, p. 13). A autora afirma ainda que

Nesse sentido, cabe lembrar as preocupações disciplinadoras da docência expostas nas propostas didáticas de Comenius (1985), 


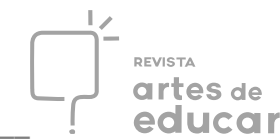

datadas de 1657. Nessas, o olhar já era enunciado como uma forma de controle fundamental à implementação do ensino coletivo, compondo, com outras condutas corporais específicas (distanciamento, seriedade, retidão, controle e contenção dos gestos e das emoções), o ritual de controle de classe, assentado na visibilidade de todos os alunos pelo professor e do professor por todos os alunos ao mesmo tempo. (FONTANA, 2011, p. 13)

Para Fontana (2011), embora a contenção e o controle dos corpos não estejam explicitados nos currículos, a instituição escolar não ignora sua importância; ao contrário, reafirma sua presença no dia a dia escolar. Essas ponderações vão ao encontro das reflexões foucaultianas a respeito da disciplina e do exercício de poder que incide sobre o corpo.

Consideramos que os processos de aprendizagem necessitam de organização, sobretudo quando estamos diante de um coletivo. Porém, nem todo aprendizado se faz sentado, nem todo aprendizado se faz calado, nem todo aprendizado se faz parado. Romper com modelos educacionais que primam pela imobilidade, que se assentam no controle absoluto da expressão corporal dos/as alunos/as, consiste num desafio a ser enfrentado, sobretudo nas séries iniciais do ensino fundamental.

A escola é um espaço coletivo de interação com o mundo e de construção de significativas experiências sociais. A ampliação para o ensino fundamental de nove anos, ampliando o tempo de permanência das crianças na escola, trouxe consigo o problema do ingresso das crianças cada vez mais cedo num modelo tradicional de educação exercido principalmente a partir dessa etapa da educação básica. E em se tratando de crianças de seis anos, recém-chegadas da educação infantil, estaria a escola alerta e preparada para lidar com as especificidades dessa faixa etária? Concordamos com Gorni, Maieski e Machado (2012), pois

Tendo em vista que nos primeiros anos do Ensino Fundamental a criança passa a descobrir de maneira gradativa o universo sistemático da aquisição do conhecimento disposto nas diversas disciplinas, é importante que este processo ocorra de maneira "fascinante", impulsionando-a a se sentir sempre mais uma investigadora do seu próprio aprendizado. Para tanto, o respeito à infância é um elemento que deve ser cuidadosamente considerado na seleção e na organização dos conteúdos de ensino. Além disso, é importante que estes sejam significativos e atraentes para o aluno, despertando o seu interesse. (GORNI; MAIESKI; MACHADO, 2012, p. 17) 
Pensamos que a transição da educação infantil para o ensino fundamental deve ser feita levando em consideração que a criança que passa de um segmento de ensino para o outro não é mais a mesma, mas carrega consigo as formas de dialogar com o mundo que foram construídas desde a sua entrada na vida escolar e seguem em permanente construção, em movimento constante, no cotejamento entre o que viveu, o que está vivendo e o que viverá, como processo e não como produto.

Mota (2012) afirma que nos documentos do MEC,

o primeiro ano do Ensino Fundamental de nove anos não é nem igual à pré-escola, nem uma repetição da antiga primeira série do Ensino Fundamental de oito anos. Assim, compreende-se que a política de Ensino Fundamental de nove anos pode ser uma das condições de possibilidade para a produção de um novo sujeito escolar de seis anos, que não é o mesmo da Educação Infantil, mas que também não é o mesmo da primeira série do antigo Ensino Fundamental. (MOTA, 2012, p. 29)

Com essas crianças sendo inseridas num contexto diferente daquele a que estavam acostumadas, fica clara a necessidade de se rever muitas práticas na escola. A recepção das crianças de seis anos no ensino fundamental não pode ser simplesmente uma integração ao ritmo de trabalho já existente, mas sim, uma adaptação adequada às suas necessidades específicas como crianças de seis anos de idade, e isso está diretamente relacionado ao direito às características próprias da infância, como o brincar, a livre expressão etc.

A Educação Infantil e o Ensino Fundamental têm formas diferentes de organização e, mesmo que em alguns casos haja uma articulação entre esses níveis educacionais, estão pautados em propostas pedagógicas que se diferenciam. Em razão disso, pode-se entender que, a partir de agora, a criança de seis anos ocupará outro lugar na escola, e isso poderá mudar também os modos de ser criança. (MOTA, 2012, p. 24)

Da forma como se manifestam os documentos oficiais sobre o ensino fundamental de nove anos, entende-se que a escola precisa ser reestruturada para atender de forma adequada as crianças de seis anos. Contudo, mudanças efetivas não foram constatadas e tão pouco medidas de adaptação ao tempo ampliado de Revista Interinstitucional Artes de Educar. Rio de Janeiro, V. 6, N.1- pág. 13-36 janeiro-abril de 


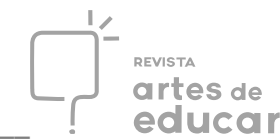

permanência na escola. Ao contrário, as crianças estão inseridas em atividades escolares num ritmo de trabalho exaustivo para sua faixa etária.

Dentro dessa lógica, o primeiro ano do ensino fundamental de nove anos, que hoje recebe crianças com seis anos de idade, tem adotado as mesmas práticas da antiga primeira série do ensino fundamental, mantendo os objetivos de escolarizar o mais rápido possível, alfabetizando o quanto antes. E, nesse contexto, o corpo das crianças vai sendo educado, moldado e produzido social e culturalmente. Retomando as reflexões de Cruz et al. (2010),

o corpo que vai à escola e ali permanece muitas horas, quieto, atento, em silêncio, ouvindo os professores e seus saberes sobre a boa higiene, a boa nutrição, a bela forma física, é o mesmo corpo que recebe paparicação, que aprende a sociabilidade da negociação e que utiliza o recreio e a ida ao banheiro para suas pequenas descompressões. Não se trata, enfim, de um corpo genérico, mas de um corpo produzido socialmente, culturalmente. (CRUZ et al, 2010, p. 61)

Sendo assim, as crianças acabam sendo obrigadas a se adequar aos padrões estabelecidos pela instituição escolar, deixando de lado as práticas lúdicas próprias da infância, que se ancoram no corpo e na expressão corporal e que, geralmente, fazem parte integrante da rotina na educação infantil.

A delicada passagem das crianças de seis anos de idade da educação infantil para o ensino fundamental pôde ser observada ao longo da pesquisa de campo. Ao acompanharmos o contexto vivenciado por essas crianças, visualizamos uma mudança significativa marcada pela passagem de um período supostamente lúdico e corporalmente ativo na educação infantil, para uma fase corporalmente "engessada" no ensino fundamental. As crianças acabavam sendo forçadas a se adaptar às práticas do ensino fundamental, as quais não estavam voltadas às suas necessidades e possibilidades de movimentação e expressão corporal, nem mesmo quando se tratava das aulas de Educação Física e Artes que foram observadas na investigação.

De fato, quando acompanhamos algumas aulas dessas áreas de conhecimento, percebemos poucos momentos em que as crianças foram incentivadas a explorar seu corpo, seus gestos e sua expressão corporal. Como ocorre comumente nas escolas, um dos poucos espaços destinados ao trabalho com a expressão corporal 


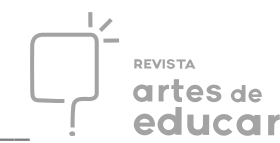

são as aulas de Educação Física, que têm como eixo de conhecimento diferentes temas da cultura corporal, considerando a expressão corporal como linguagem (COLETIVO DE AUTORES, 1992).

Trabalhar com o corpo e a expressão corporal na escola fica restrito, muitas vezes, às aulas de Educação Física, durante um tempo limitado. Na entrevista realizada com Prof. ${ }^{a}$ Helena, da Educação Física, ouvimos o seguinte:

As aulas de Educação Física proporcionam práticas com todos os níveis de ensino. Para quem é da Educação Física é mais fácil realizar trabalhos com o corpo, porém o tempo é limitado. O tempo não te dá muita opção. Você dá um aquecimento e o tempo voa, diminui o tempo de jogar dos alunos e eles ficam bravos. (Prof. ${ }^{a}$ Helena)

$\mathrm{Na}$ escola pesquisada, além do tempo escasso destinado às aulas de Educação Física, também observamos certa precariedade em relação ao local destinado a essas aulas: a quadra esportiva era pequena, toda rachada, com ondulações e sem cobertura. Defendemos que uma aula pode ser desenvolvida em diferentes espaços, não necessariamente numa quadra. No entanto, tal precariedade chama a atenção e diz também do lugar desse componente curricular na escola.

Além disso, com relação aos conhecimentos propostos, as atividades realizadas com ambas as turmas foram mais voltadas para esportes como futebol, handebol e alguns jogos de tabuleiro, brinquedos de montar e bonecas na pequena área da quadra quase sem sombra. Essa situação trouxe-nos algumas reflexões sobre os modos como as aulas de Educação Física são desenvolvidas, seus espaços e possibilidades: quase sempre o mesmo espaço, os mesmos esportes e, nesse caso, em condições limitadas e precárias.

Por outro lado, ao observarmos essas aulas, muitas recordações nos vieram à memória, trazendo boas lembranças de nossas aulas no ensino fundamental, com atividades mais livres e espaços mais amplos. Contudo, lembramos igualmente que as aulas de Educação Física se pautavam quase sempre nos mesmos esportes, no famoso "jogar bola". Mesmo assim, fica na memória o nosso gosto e prazer por essas propostas, por serem mais livres e divertidas que as demais aulas. Ayoub (2001) confirma essa impressão: 


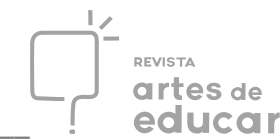

É comum vermos crianças sedentas pela aula de educação física quando chegamos às escolas; salta-me aos olhos imagens de "explosão corporal" diante da possibilidade de "libertar-se das carteiras escolares" que funcionam, na maioria das vezes, como "armaduras corporais", até mesmo em pré-escolas (AYOUB, 2001, p. 58).

A partir dessas constatações, às quais acrescentamos o fato de não ser frequente as escolas possuírem um parque, levantamos o seguinte questionamento: será que os momentos de Educação Física são a única possibilidade de "libertar as crianças das carteiras escolares?” Bracht (1999) observa que

à educação física é atribuída uma tarefa que envolve as atividades de movimento que só pode ser corporal, uma vez que humano. No entanto, a educação do comportamento corporal, porque humano, acontece também em outras instâncias e em outras disciplinas escolares. (BRACHT, 1999, p. 72)

A educação física escolar tem a responsabilidade de tratar pedagogicamente as práticas corporais (SILVA; DAMIANI, 2005) culturalmente construídas pelo ser humano ao longo da história. Podemos afirmar que a aula de Educação Física é um espaço privilegiado dentro da escola para as práticas corporais e o estudo da expressão corporal como linguagem. No entanto, a educação do corpo, tema sobre o qual estamos refletindo nesta pesquisa, é mais ampla do que aquilo que acontece nos espaços-tempos das aulas de Educação Física, pois está presente em todas as situações da vida escolar.

Nessa mesma direção, a "educação do comportamento corporal", problematizada por Bracht (1999), relaciona-se com a ideia de controle do corpo, por meio do controle do comportamento, que é exercido não só nas aulas de Educação Física, mas em vários outros momentos escolares, reafirmando a prática de uma educação corporal que busca construir corpos dóceis.

Outro espaço oportuno para contemplar a expressão corporal e as possibilidades de criação das crianças são as aulas de Arte. Quando pensamos em arte, precisamos considerar suas variadas linguagens: Artes Cênicas, Artes Visuais, Música, Dança, entre outras. Crianças reunidas num contexto com variados recursos materiais e incentivadas a "inventar" têm preciosa oportunidade criativa. Um simples afastar das carteiras e o uso do espaço livre para conhecer, produzir e experimentar o 


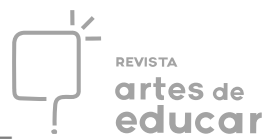

corpo e a arte, criar desenhos, danças, teatros, músicas e gestos fazem dos espaçostempos das aulas de Artes uma experiência única. Por meio de uma história contada, ou de uma história construída, ou de uma história interpretada por gestos, o quão instigante não seria estar ali, aprendendo e divertindo-se?

Contudo, na maioria das aulas de Arte observadas, somente presenciamos propostas com folhas brancas de papel sulfite e lápis coloridos, para desenhar algo quase sempre relativo a datas comemorativas. Observamos também que as crianças costumavam levar o desenho finalizado para a professora apreciar e ela parecia ter o costume de procurar algum detalhe que não estava de acordo com as suas expectativas, solicitando que o desenho fosse refeito (por exemplo, a árvore pintada de azul, a pequenina casa no canto superior direito da folha ou a representação de um balão junino fora dos padrões).

As crianças podem descobrir, sonhar, inventar o mundo de uma maneira peculiar. Elas podem desenvolver práticas criativas que, infelizmente, são limitadas por rígidas formas escolarizadas de pensar a educação e o conhecimento.

A criatividade está muito presente no universo infantil, porém é comum encontrarmos escolas nas quais as aulas de Arte são desenvolvidas de maneira empobrecida, sem planejamento, sem considerar as possibilidades criativas dos/as alunos/as, sem entender a Arte como uma forma de produção de conhecimento. Muitas vezes, essas aulas são frequentemente associadas à preparação de presentes estereotipados aos familiares ou de enfeites para as festas escolares relacionados a datas comemorativas que constam no calendário escolar, ou mesmo a tempos ociosos com lápis e papel, como exemplificado anteriormente.

Segundo Albano (2004), é importante reconhecer a Arte como linguagem, como forma de representação e expressão, e existem alguns pontos que são importantes para as práticas artísticas: planejamento, tempo, espaço, respeito ao nível de desenvolvimento de cada criança e vivências significativas. Esses pontos devem ser somados a uma sequência de experiências planejadas intencionalmente, para a construção de um conhecimento significativo.

Em geral, a Arte na escola está relacionada a "pintar um desenho"; raramente a encenar uma peça, dançar uma coreografia ou compor uma música. E, ainda, muitas vezes nos esquecemos de que a Arte também é fruição, mobiliza 


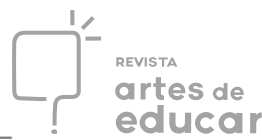

sentimentos ao observarmos um quadro, ouvirmos uma música, assistirmos a uma peça teatral ou a uma apresentação de dança.

Após analisarmos tanto a inadequação do espaço quanto os modos de organização das aulas de Educação Física e Arte, convencemo-nos da ruptura que as crianças experimentam ao deixar o contexto, muitas vezes lúdico, da educação infantil, e adentrar num contexto menos flexível, sem incentivo à criatividade, à experimentação, e com foco na "absorção" de conteúdos preestabelecido. O que acontece geralmente nesse período de transição é que as crianças são forçadas a estar num lugar que não está preparado e nem sensibilizado para suas peculiaridades, afinal, as crianças não deixam de ser crianças quando ingressam no ensino fundamental.

Cabe observar que no sistema anterior, quando o ingresso no ensino fundamental se dava aos sete anos de idade, a transição não era menos abrupta, mas agora acreditamos ser mais urgente a atenção a esse aspecto, já que a antecipação em um ano deixa as crianças ainda mais expostas a esse processo. Entretanto, a mesma escola que cerceia e limita os modos de organização e de ação das crianças, pode abrir espaço para outras possibilidades de relação com as crianças, seus gestos e sua expressão corporal.

No segundo semestre de observação, acompanhamos a turma do $1^{\circ}$ ano $\mathrm{B}$, com a Prof. a Sara. Ali, embora crianças estivessem submetidas às mesmas regras disciplinares que pautam a rotina escolar, como as filas, os sinais de entrada/saída, a inibição da livre movimentação, bem como a imposição de silêncio, de horários etc., notamos que a Prof. ${ }^{\text {a }}$ Sara estava disposta a buscar novas possibilidades e procurava oferecer experiências diferentes e instigantes para sua turma, utilizando, inclusive, a sua própria criatividade no exercício da docência.

Durante esse período, acompanhamos a turma em diversas atividades planejadas pela professora, nos diferentes espaços-tempos da escola. Os dias em que observamos a turma na sala de aula, percebemos que a posição das carteiras mudava: em alguns dias as carteiras estavam em duplas, quartetos ou em formato circular, sendo que as crianças podiam escolher livremente o local onde iriam se sentar. Essa situação remete à pesquisa de Assaritti (2015), na qual a autora mostra que o olhar sensível das professoras pode fazer com que outras possibilidades tomem forma. 


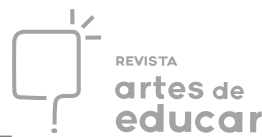

O olhar sensível das professoras na escola percebe as diferenças na expressão dos alunos que antes se enfileiravam e agora se sentam em roda, que percebe outras possibilidades de guiar o grupo que não em fila. A potência desse olhar é capaz de multiplicar as imagens de resistência na escola, nas salas de aula e, principalmente, no currículo, para que estas relutâncias diárias sejam legitimadas, para que então, as carteiras já estejam em formato de U quando a professora entra com as crianças na sala, para que ela não precise todos os dias desenfileirá-las.

A cultura, os modos, valores e formas de ser e estar, são incorporados por meio primeiramente do contato do corpo com o mundo. Os sentidos são também educados. O saber sobre o mundo antes de ser inteligível é sensível, ou seja, nossos sentidos são plenos de sons, cores, sabores, odores e texturas, que nos contam sobre o mundo. (ASSARITTI, 2015, p. 156)

Assim, percebemos que o olhar sensível de Sara mediava o contato das crianças com o mundo e transformava suas práticas cotidianas. Por exemplo, todo início de aula, Sara costumava fazer com as crianças um alongamento corporal. Pelo que percebemos, as crianças já sabiam como funcionava o alongamento, como algo já combinado com a turma. Assim que todos se acomodavam na sala, Sara ficava de pé na frente da sala e cada aluno se levantava e ficava em pé próximo da sua carteira. Sara conduzia os gestos, sendo que a cada dia os gestos se alternavam. As crianças repetiam os gestos em conjunto e nós não presenciamos nenhuma criança se recusando a fazer. Sara finalizava o alongamento com exercícios de respiração, como o conhecido "inspira, expira". Na entrevista que realizamos com Sara, ela disse que o alongamento "é uma possibilidade de trabalhar a respiração, os gestos e o relaxamento da tensão corporal, para assim começar melhor as atividades do dia”.

Nos dias em que acompanhamos a turma, Sara começava as aulas com roda de conversa, em que as crianças escolhiam sobre o que gostariam de falar. Dessas conversas, emanavam temáticas e projetos de trabalhos coletivos, cuja criatividade e envolvimento das crianças era muito interessante. Dentre eles, foi marcante para nós o projeto "Brincadeiras Antigas", no qual a turma reuniu informações sobre essas brincadeiras por meio pesquisas e utilizando correspondências com as famílias. A partir disso, elas montaram materiais sobre brincadeiras antigas realizadas nos tempos dos seus pais e avós, e convidaram os familiares para brincar no pátio da escola, numa ação conjunta que possibilitou às crianças compartilhar e experimentar na escola os aprendizados estudados no projeto. 


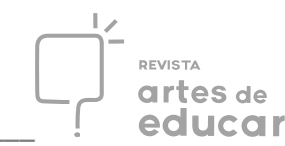

Outro projeto que chamou nossa atenção versou sobre a confecção de bonecos indígenas com reutilização de materiais, em que as crianças coletaram terra do jardim (abandonado) da escola em garrafas PET, fazendo uma base para a confecção de bonecos a partir das temáticas estudadas. Semelhante a esse, o projeto de confecção de peças de dominó gigante foi uma produção coletiva da turma com o uso de caixas de leite e papéis coloridos, e com essas peças, as crianças puderam aprender matemática de uma forma diferente e lúdica.

Grande parte das atividades propostas por Sara objetivava a partilha de ideias por meio do diálogo, fazendo com que o aprendizado fosse produzido na interação entre os pares, com a mediação dela. A todo momento as crianças se mostravam interessadas em participar, criar e construir com Sara. Nesses exemplos de práticas propostos pela professora, foi possível perceber que a construção das relações e das atividades não era colocada de forma imposta, causando reações de resistência nas crianças, mas sim, incitando a participação efetiva com momentos de trocas e aprendizagem constante.

Essas práticas vão ao encontro da perspectiva histórico-cultural do desenvolvimento humano, a qual enfatiza a importância das relações sociais para o desenvolvimento do sujeito e tem como princípio a ideia de que o ser humano, desde o seu nascimento, interage com o contexto e vai aos poucos se apropriando das significações histórico-sociais. No contato com o outro, o sujeito vai se desenvolvendo no contexto sócio-histórico que, segundo Fontana e Cruz (1997, p. 57), é o princípio orientador da abordagem vigotskiana.

Segundo esse princípio, tudo o que é especificamente humano e distingue o homem de outras espécies origina-se de sua vida em sociedade. Seus modos de perceber, de representar, de explicar e de atuar sobre o meio, seus sentimentos em relação ao mundo, ao outro e a si mesmo, enfim, seu funcionamento psicológico, vão se constituindo nas suas relações sociais. (FONTANA; CRUZ, 1997, p. 57)

Os seres humanos se constituem nas relações sociais, nas interações com o outro e com o contexto e, para que isso aconteça, é necessário que haja a mediação. $\mathrm{Na}$ escola, as crianças iniciam seu processo da educação formal, no qual os conhecimentos são ensinados e aprendidos num determinado espaço e num Revista Interinstitucional Artes de Educar. Rio de Janeiro, V. 6, N.1-pág. 13-36 janeiro-abril de 2020: "Educação: Corpo em movimento II." - DOI: 10.12957/riae.2020.45009 


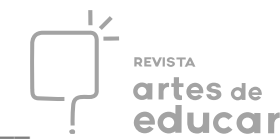

determinado tempo de forma deliberada, intencional. Os sujeitos envolvidos no cenário escolar assumem o papel do "outro", constituindo as relações sociais e principalmente assumindo a função de mediadores na relação das crianças com o mundo do conhecimento sistematizado. A professora, como adulto de referência para as crianças, medeia, orienta, destaca conhecimentos que considera importantes, analisa situações, sugere construções lógicas e racionais, apresenta novas perspectivas sobre a vida que os rodeia etc. Nessas ações, a professora leva as crianças a construírem seus pensamentos e ações, reestruturando sentidos e significações.

Muitas e diferentes possibilidades foram observadas no curto espaço de tempo em que acompanhamos o $1^{\circ}$ ano B. Em conversas com a Prof. ${ }^{a}$ Sara, pudemos conhecer algumas de suas ideias, mas principalmente vivenciamos as experiências que ela proporcionava à turma nos momentos de observação. Na entrevista, ela falou de sua visão em relação à educação do corpo:

Eu acho que o corpo é de fundamental importância. A gente aqui na escola, visa mais o cérebro, aliás a educação visa mais o cérebro, pelo menos antigamente. Hoje em dia, temos um pouco mais de abertura. Já antigamente, as crianças não podiam nem abrir a boca, agora as crianças têm liberdade, mas não é o ideal ainda. Tem outra coisa, as crianças vêm com um outro modo, outro olhar, então você não consegue ficar com elas paradas. Você viu como eles correm para ir ao lixo? Eles correm, andam... eu costumo deixar eles andarem. (Prof. ${ }^{a}$ Sara)

Nós, educadores e educadoras, podemos desenvolver propostas de ensino que considerem o desejo de liberdade das crianças e que sejam, ao mesmo tempo, significativas para o aprendizado dos conhecimentos escolares. Para ensinar e conviver com as crianças na escola é necessário se permitir a aprender junto com elas, compreender que o aprendizado se dá numa via de mão dupla; que o conhecimento não está nem no/a aluno/a e nem no/na professor/a, mas no encontro entre eles, um "encontro entre mundos", nas palavras de Freire (1997). Acreditamos que existem alternativas interessantes para apreensão desse conhecimento, dentre elas, destacamos as experiências que se dão no/pelo corpo, de maneira coletiva, feitas de forma intencional e deliberada, compondo o planejamento do/a professor/a. 


\section{Considerações finais}

Diante do exposto, fica clara a urgência de um olhar mais aberto para o papel da escola na vida das crianças, pois ocorreram transformações ao longo da história, e algumas práticas cristalizadas precisam ser questionadas e superadas para melhor atender aos novos sujeitos, que interagem e aprendem de maneiras diferentes.

Pensar nas múltiplas formas de aprender e ensinar é um desafio posto para a instituição escolar e para as dedicadas pessoas implicadas no processo. Repensar a escola, seus modelos e valores, repensar principalmente suas práticas, a fim de construir junto com as crianças novas formas de se manifestar, de explorar o mundo e de construir conhecimento, consiste num grande desafio para o campo da educação.

Nosso percurso investigativo revelou como a instituição escolar na atualidade continua investindo no controle e disciplinamento do corpo, concentrando, em sua materialidade, práticas, liberdades e interdições em seus diversos processos de educação do corpo. As observações feitas mostram que raros são os momentos em que as crianças podem agir livremente, expressar-se sem que seus gestos e comportamentos fossem tolhidos por diferentes regras. Na sala de aula, no recreio, nos corredores, nos horários de entrada e saída, e em muitos outros momentos, encontramos alguém supervisionando as atividades dos/as alunos/as editando normas que inibem suas manifestações corporais, seus gestos e sua expressão corporal.

Ainda ecoam na memória alguns exemplos de falas dirigidas às crianças em diferentes momentos: quando as crianças estavam correndo no recreio - "pode parar de correr, porque você pode cair e machucar!"-; explorando espaços pelos corredores - “onde você vai? Sua sala é por ali, não tem nada que ficar andando por aí!"-; movimentando-se pela sala de aula - "fica sentado na cadeira, não é para ficar levantando e sentando não"-; ou simplesmente, pedindo para ir ao banheiro - "agora não é hora!".

Essas atitudes que vigiam, reprimem e proíbem demonstram que a escola ainda tem no controle e na disciplina suas principais referências, cerceando ações cotidianas, as quais não oferecem perigo às crianças nem, necessariamente, atrapalham o andamento das demais atividades, sob justificativas frágeis de segurança ou de interferência no ritmo da aula. Essas práticas disciplinadoras reforçam a ideia de que quanto menos se mexerem, menos problemas causarão, ou, ainda, enfatizam a Revista Interinstitucional Artes de Educar. Rio de Janeiro, V. 6, N.1- pág. 13-36 janeiro-abril de 


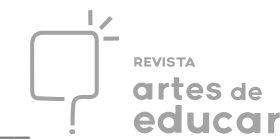

concepção de que a disciplina dos corpos é uma das principais (se não for a principal) tônicas para o funcionamento da instituição escolar.

Entender que a escola é um local onde a disciplina se faz necessária, pois há a necessidade de criar formas de convivência e socialização viáveis, não significa aceitar a disciplina exercida de forma exagerada e inadequada, que coage, inibe e proíbe diversas manifestações, entre elas as corporais, que fogem dos padrões, das tradições, dos valores socialmente impostos e que quase nunca são problematizados nos processos de ensino e aprendizagem.

Como vimos discutindo, a educação do corpo na escola é atravessada por práticas que ensinam, sobretudo, a controlar as manifestações corporais e a gestualidade. No entanto, trata-se de um processo complexo, no qual também pudemos identificar, nas brechas do cotidiano, espaços em que o controle escapa e tanto professores/as quanto crianças, experimentaram outras relações na escola. São, principalmente, nessas relações que as crianças nos ensinam formas diferentes de vivenciar o cotidiano escolar, ensinando-nos sobre sua maneira lúdica e criativa de se fazerem pessoas. Elas aprendem apesar de nossas tentativas de imobilizá-las para que aprendam. Elas aprendem, inclusive, a suportar nossos modelos quadrados de sujeição. Resistem a eles. Os vencem. Vivem. (PROBST; KRAEMER, 2012, p. 518). É importante estarmos sensíveis a essas manifestações, pois são elas que podem nos levar a projetar juntos outras possibilidades de educação e, especialmente, de educação do corpo.

\section{REFERENNCIAS}

Albano, A. A. A Arte como base epistemológica para uma Pedagogia da Infância. São Paulo: Caderno Temático de Formação 2 - Educação Infantil: construindo a Pedagogia da Infância no município de São Paulo, 2004.

ASSARITTI, D. S. A educação do corpo das crianças na escola em narrativas do cotidiano. 2015. 252 p. Dissertação (Mestrado em Educação) - Faculdade de Educação, Universidade Estadual de Campinas, Campinas, São Paulo.

AYOUB, E. Reflexões sobre a educação física na educação infantil. Revista Paulista de Educação Física, São Paulo, supl.4, p.53-60, 2001. 


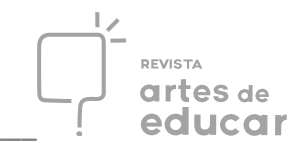

BARBOSA, R. C. A disciplina e as táticas no universo escolar segundo Michel Foucault: a anatomia política do detalhe. Revista Espaço Acadêmico, Maringá, n.74, ano VII, julho/2007.

BRACHT, V. A constituição das teorias pedagógicas da educação física. Caderno Cedes 48: Corpo e Educação. Campinas, SP: Centro de Estudos Educação e Sociedade, 1999. p.69-88.

COLETIVO DE AUTORES. Metodologia do ensino de educação física. São Paulo, SP: Cortez, 1992.

CRUZ, A. C. J. et al. Corpo: sexualidade, gênero, raça e etnia. In: ABRAMOWICZ, A.; MORUZZI, A. B. (Orgs). O plural da infância: aportes da sociologia. São Carlos, SP: EdUFSCar, 2010.

FONTANA, R. A. C. O corpo também ensina: mediações da linguagem não verbal no trabalho docente. Revista Espaço Pedagógico, Passo Fundo, RS, v. 18, n. 1, p. 9-22, jan. /jun. 2011.

FONTANA, R. A. C.; CRUZ, M. N. Psicologia e trabalho pedagógico. São Paulo, SP: Atual, 1997.

FOUCAULT, M. Vigiar e punir: nascimento da prisão. 5. ed. Petrópolis, RJ: Vozes, 1987.

FOUCAULT, M. Microfísica do poder.Tradução de Roberto Machado. 30a reimpressão. Rio de Janeiro, RJ: Graal, 2012.

FREIRE, P. Pedagogia da autonomia: saberes necessários à prática educativa. Rio de Janeiro, RJ: Paz e Terra, 1997.

GINZBURG, C. Mitos, emblemas e sinais: morfologia e história. São Paulo, SP: Companhia das Letras, 1989.

GORNI, D. A. P.; MAIESKI, S.; MACHADO, V. R. B. F. Ensino Fundamental de nove anos: os desdobramentos de uma política educacional. Seção Temática: $\mathbf{O}$ Ensino Fundamental de nove anos. Revista de Educação PUC-Campinas, Campinas, SP, n. 17(1), p. 9-22, jan./jun., 2012.

GUEDES-PINTO, A. L.; FONTANA, R. A. C. Apontamentos teóricometodológicos sobre a prática de ensino na formação inicial. Educação em revista, Belo Horizonte, MG, n. 44, p. 69-87, dez. 2006.

MOTA, M. R. A. O lugar das crianças de seis anos no ensino fundamental de nove anos. Revista de Educação PUC-Campinas, Campinas, SP, n. 17(1), p. 23-31, jan./jun., 2012.

PROBST, M.; KRAEMER, C. Sentado e quieto: o lugar do corpo na escola. Atos de Pesquisa em Educação, Blumenau, SC, v.7, n.2, p.507-519, mai./ago. 2012.

Revista Interinstitucional Artes de Educar. Rio de Janeiro, V. 6, N.1-pág. 13-36 janeiro-abril de 2020: "Educação: Corpo em movimento II." - DOI: 10.12957/riae.2020.45009 
SOARES, C. L. Educação do corpo (verbete). In: GONZÁLEZ, F. J.; FENSTERSEIFER, P. E. (Orgs). Dicionário Crítico de Educação Física. 3. ed. Ijuí, RS: Unijuí, 2014.

SOARES, C. L.; ZARANKIN, A. Arquitetura e educação do corpo: notas indiciais. Revista Rua, Campinas, SP, n. 10. p. 23-35, mar. 2004.

SILVA, A. M.; DAMIANI, I. R. (Orgs.). Práticas corporais: gênese de um movimento investigativo em Educação Física. Florianópolis, SC: Nauemblu Ciência \& Arte, 2005.

TURA, M. L. R. A observação do cotidiano escolar. In: ZAGO, N. et al. (Orgs). Itinerários de pesquisa: perspectivas qualitativas em Sociologia da Educação. Rio de Janeiro, RJ: DP\&A, 2003.

\footnotetext{
i Graduada em Pedagogia pela Universidade Estadual de Campinas (Unicamp). E-mail: danielleabargas@gmail.com. Campinas/SP. ORCID: http://orcid.org/0000-0003-3426-8657

ii Licenciada, Mestre e Doutora em Educação Física pela Universidade Estadual de Campinas (Unicamp). Atualmente é docente da Faculdade de Educação da Unicamp. E-mail: ayoub@ unicamp.br. Campinas/SP. ORCID: http://orcid.org/0000-0003-2160-0585

iii Licenciada em Educação Física e mestra em Educação pela Universidade Estadual de Campinas (Unicamp). Atualmente é docente no Ensino Básico Técnico e Tecnológico (EBTT) do Instituto Federal de Educação, Ciência e Tecnologia Baiano - Campus Santa Inês. E-mail: dolores.assaritti@gmail.com. Santa Inês/BA. ORCID: https://orcid.org/0000-0002-3829-7984

iv Licenciada em Educação Física pela Escola Superior de Educação Física de Jundiaí (ESEFJ), Mestra em Educação pela Universidade Estadual de Campinas e Doutora em Educação pela mesma instituição. E-mail: jscarazzatto@hotmail.com. Campinas/SP. ORCID: https://orcid.org/0000-0002-6232-6060

${ }^{v}$ Licenciada em Educação Física pela Pontifícia Universidade Católica de Campinas (PUCCamp), Mestra em Educação Física pela Universidade Federal de Santa Catarina (UFSC) e Doutora em Educação pela Universidade Estadual de Campinas (Unicamp). Atualmente é docente dos cursos de Pedagogia e Educação Física da Faculdade Anhanguera de Sumaré (FSU). E-mail: mdpassis@yahoo.com.br. Campinas/SP. ORCID:https://orcid.org/0000-0002-5917-0886
}

${ }^{6}$ A pesquisa foi aprovada pelo Comitê de Ética em Pesquisa da Universidade Estadual de Campinas em 2014, sob parecer consubstanciado n. 959.220. 